\title{
Long-term morphological evaluation of porous poly-DL-lactic acid for soft tissue augmentation
}

\author{
Yukawa Ken*, Tachikawa Noriko, Munakata Motohiro, Akino Norio, Kasugai Shohei \\ Department of Oral Implantology and Regenerative Dental Medicine, Tokyo Medical and Dental University, Tokyo, Japan; \\ Corresponding Author: yukairm@tmd.ac.jp
}

Received 20 September 2013; revised 20 October 2013; accepted 27 October 2013

Copyright (C) 2013 Yukawa Ken et al. This is an open access article distributed under the Creative Commons Attribution License, which permits unrestricted use, distribution, and reproduction in any medium, provided the original work is properly cited.

\begin{abstract}
Soft tissues are important for aesthetic considerations in implant therapy. The purpose of this study was to investigate soft tissue augmentation by using porous poly-DL-lactic acid (PDLLA) shaped as a tablet, with a diameter of $5.0 \mathrm{~mm}$ and a height of $2.0 \mathrm{~mm}$. Porous PDLLA was implanted between the periosteal and epithelial tissues in 25 rats that were sacrificed at 1, 2, 4, 12 , and 24 weeks. The average height of the PDLLA scaffolds at approximately 24 weeks was $1.85 \pm 0.08 \mathrm{~mm}$, and the molecular weight decreased with time. Sinusoidal capillaries at 1 week, connective tissues at 4 weeks, and necrotic tissues at 24 weeks were observed more than other periods. At $\mathbf{2 4}$ weeks, the connective tissue surviving in the pores was confirmed to contain blood vessels; therefore, blood vessels are considered to be critical for the survival of soft tissue in scaffold pores. In this study, PDLLA was found to be useful for soft tissue augmentation in the long term. Although the molecular weight of PDLLA decreased with time, the height of the PDLLA scaffolds was preserved. The connective tissue surviving in the pores of the scaffolds at $\mathbf{2 4}$ weeks were associated with blood vessels. Further studies are necessary to investigate the optimal scaffold shape and surface characteristics to improve the penetration of blood vessels.
\end{abstract}

Keywords: Poly-DL-Lactic Acid (PDLLA); Soft Tissue Augmentation; Biodegradation; Porous; Scaffolds

\section{INTRODUCTION}

Tissue engineering for dental implant therapy pri- marily relies on bone regeneration as dental implants are inserted into bone [1]. However, for the prognosis of implant therapy, soft tissues such as gingiva are as important as hard tissues such as the bone. Additionally, bone resorption is a critical factor for maintaining the gingival margin line to achieve aesthetic success. In the case of anterior implant therapy, black triangles often appear at the interdental papilla, and in the absence of sufficient soft tissue, plaque and bacteria can easily adhere to implants, particularly because the complicated shape and rough surface of implants complicate removal of plaque and bacteria [2]. Patients who receive implant therapy often have insufficient soft tissue volume. Therefore, soft tissue augmentation, particularly around dental implants, is an important concern.

Soft tissue augmentation is usually performed using autogenous materials through connective tissue grafts (CTGs) [3]. Harvesting in the case of CTGs is complex because the operator treats the donor sites and thus requires additional chair time. Not all patients will have sufficient connective tissue for grafting, and even if they have sufficient tissue, the CTG is absorbed to $76 \%$ of its original size during the transplantation operation and over time [4]. Preparation of repair materials prior to the operation may solve this problem. Regarding autogenous materials, McGuire reported a living tissue-engineered human fibroblast-derived dermal substitute [5]. The method, however, used for preparing this construct is complex and requires time and resources. Gao [6] reported that allogeneic materials are derived from animal tissue, e.g., bovine or porcine tissue. However, even when allogeneic materials are completely sterilized, they present the risk of causing unknown disorders [7]. The use of synthetic materials may resolve these problems. Wei et al. [8] reported the preparation of scaffolds from biocompatible and porous PLLA, PDLLA, and PLGA materials. Porous PLLA has been studied for the reconstruction of nerves and blood vessels $[9,10]$. However, 
no reports have addressed soft tissue augmentation and reconstruction.

The aims of the present study were to investigate synthetic, biocompatible, and porous PDLLA for soft tissue augmentation.

\section{MATERIALS AND METHODS}

\subsection{Materials}

Porous pure PDLLA $(\mathrm{D} / \mathrm{L}=50 / 50 \mathrm{~mol} \%$; porosity calculated from apparent density, $70 \%$; pore diameter, 40 - $400 \mu \mathrm{m}$ ) was provided by Takiron (Hyogo, Japan) (Figure 1) and was shaped as a tablet with a diameter of $5.0 \mathrm{~mm}$ and a height of $2.0 \mathrm{~mm}$. The molecular weight $(\mathrm{Mw})$ of the PDLLA was $130.9 \mathrm{kDa}$.

\subsection{Animals}

In these experiments, twenty-five 8-week-old male Wistar/ST rats were used. The animals were kept under standard housing conditions and allowed ad libitum access to water and a standard dry diet. The 25 rats were divided into 5 groups containing 5 rats each, based on the time points of $1,2,4,12$, and 24 weeks.

The rearing of animals and animal experiments were performed at the Institute of Laboratory Animals and were conducted in accordance with the guidelines for animal experimentation at Tokyo Medical and Dental University (approval no.0110231B). Anesthesia was induced using inhaled diethyl ether and then maintained by intramuscular administration of ketamine hydrochloride $(1.64 \mathrm{ml} / \mathrm{kg}$ body weight $)$ and celactal $(0.36 \mathrm{ml} / \mathrm{kg}$ body weight). After skin incision, the panniculus between the epithelium and periosteum was exfoliated via blunt dissection. A PDLLA scaffold was placed onto the periosteum, and the 4 corners of the scaffold were fixed using $5 / 0$ nylon sutures (SOFTRETCH, GC, Tokyo, Japan) (Figures 2 and 3). Two scaffolds were placed for 3 rats in each of the 4-week, 12-week, and 24-week groups, where one scaffold was fixed with nylon sutures and the other was not. All skin incisions were closed using 4/0 nylon sutures.

The animals were killed at 1, 2, 4, 12, and 24 weeks after surgery by an overdose of pentobarbital-natrium. The scaffolds were removed together with the cranial bone and surrounding tissues. The other scaffolds that were not fixed with nylon sutures were removed with the surrounding tissue. All samples were fixed with $10 \%$ formalin solution. Five samples from each group were embedded in paraffin for $\mathrm{H} \& \mathrm{E}$ staining. Other samples, which were not fixed with nylon sutures, were used for measurement of molecular weight.

\subsection{Measurement of Scaffold Height}

The height of the scaffold was measured to evaluate

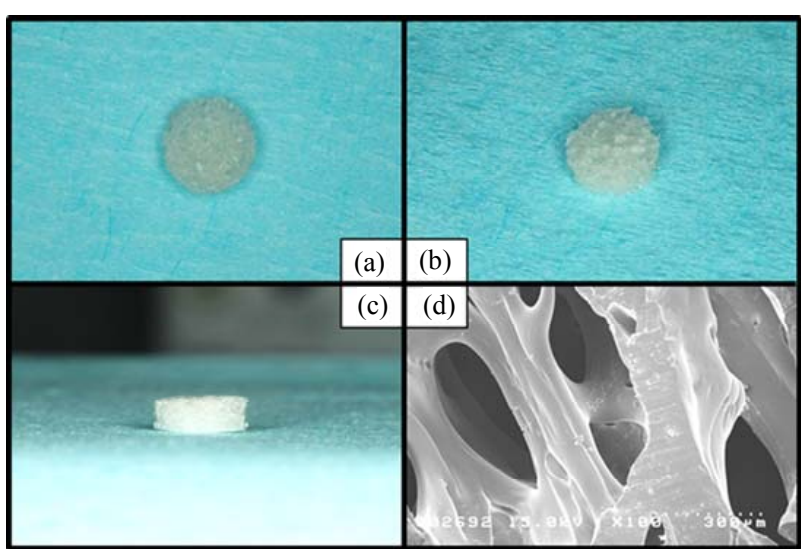

Figure 1. (a) Upper view of porous PDLLA (diameter $=5.0$ $\mathrm{mm}$ ). (b) Bird view of the material. (c) Side view of the material (height $=2.0 \mathrm{~mm}$ ). (d) $\mathrm{SEM}$ image of the cross section obtained on cutting with the microtome.

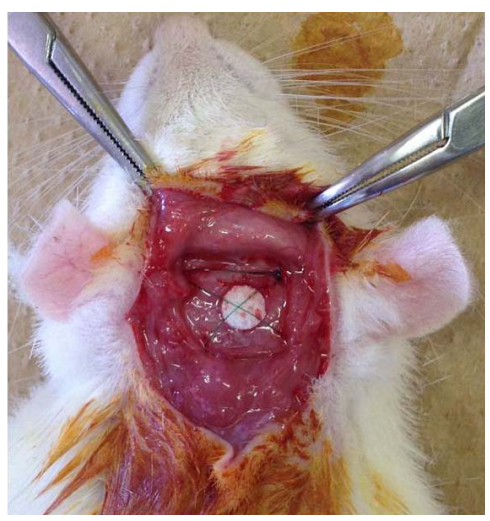

Figure 2. The material was fixed at the 4 corners with $5 / 0$ nylon sutures.

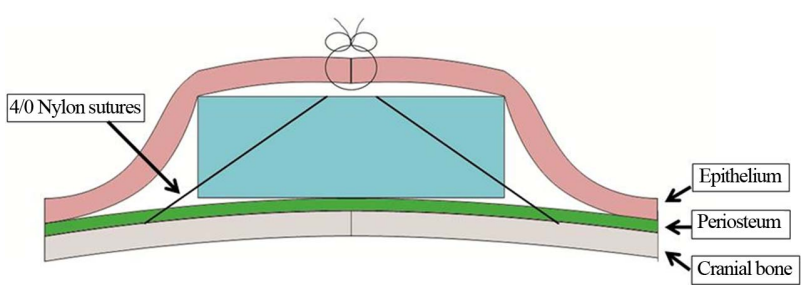

Figure 3. The material immediately after the operation (pattern diagram).

the preservation of the scaffolds. When the animals were sacrificed, the scaffolds were measured with digital calipers to determine their height. The height was provided for the line from the top position with more than twothird of the former material's diameter to the lower base.

\subsection{Measurement of Molecular Weight}

When the rats were sacrificed, the samples that were not fixed with nylon sutures were used for the measurement of molecular weight over time by using gel permeation chromatography (GPC; HLC-8320GPC; Tosoh 
Corporation, Japan).

\subsection{Histological Analyses}

The connective tissue area, sinusoidal capillaries, and necrotic tissue were measured to evaluate the replacement of the scaffold with connective tissue (Image J software) (Figure 4). The diameter of the connective tissue was measured in 5 slides at 24 weeks. Connective tissue that was narrow in the middle or that existed around the PDLLA was measured by dividing by the minimal width (Image J software $1.46 \mathrm{r}$, National Institutes of Health, USA).

\subsection{Statistical Analysis}

The values have been expressed as mean \pm standard deviation values. Statistical analysis was performed by one-way analysis of variance (ANOVA) and Tukey's HSD test or the Games-Howell test, if necessary, by using the SPSS software for Windows (PASW Statistics 18.0; SPSS Inc., Japan).

\section{RESULTS}

\subsection{Measurement of Scaffold Height}

The scaffold height was measured (Figure 5), and some of the values were at least $2.00 \mathrm{~mm}$ because the samples included tissues on the top of the scaffold. Significant differences were observed between the height at 24 weeks and those at 1,2 , and 4 weeks $(\mathrm{p}<0.05)$.

\subsection{Measurement of Molecular Weight}

The molecular weight was measured (Tables 1 and 2), and significant differences were observed over time $(\mathrm{p}<$ $0.05)$.

\subsection{Histological Analyses}

PDLLA was not observed on the slides because it was dissolved by organic solvents such as xylene that were used during paraffin embedding. However, the volume and shape of the tissue in the scaffold pores were main-

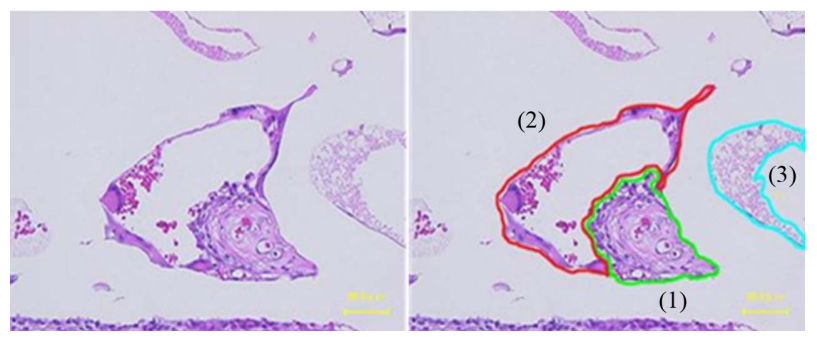

Figure 4. The left figure shows an unprocessed image. The right figure has been processed by drawing lines along the lines of each tissue, (1) connective tissue, (2) sinusoidal capillary, and (3) necrotic tissue by using the Image J software.

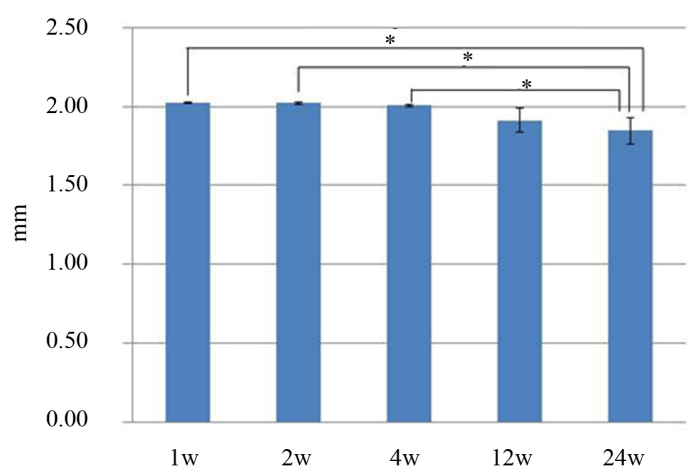

Figure 5. The material height was measured with digital calipers. There were significant differences between the values obtained at 24 weeks and those obtained at 1, 2 and 4 weeks.

Table 1. Results for molecular weight of scaffold.

\begin{tabular}{ccccc}
\hline Week (s) & 0 & 4 & 12 & 24 \\
Mean \pm S.D. (kDa) & $220.3 \pm 1.58$ & $181.9 \pm 1.01$ & 106.4 & $66.5 \pm 8.25$ \\
\hline
\end{tabular}

Table 2. Results of the retention rate of molecular weight.

\begin{tabular}{ccccc}
\hline Weeks & 0 & 4 & 12 & 24 \\
0 & $*$ & & & \\
4 & $*$ & $*$ & & \\
12 & $*$ & $*$ & $*$ \\
24 & & & \\
\hline
\end{tabular}

tained. Therefore, we assumed that the blank areas on the slides had been occupied by the scaffolds.

The areas of different types of tissue were measured at each time point (Figure 6). Many sinusoidal capillaries were observed at 1 week. At 4 weeks, much more connective tissue was observed. At 12 weeks, the amount of necrotic tissue increased.

At 1 week, the shape of the scaffold had not changed (Figure 7(a)). Many sinusoidal capillaries that contained endothelial cells and erythrocytes were observed. Immature connective tissue was also observed (Figures 7(b)(d)). Inflammatory cells were observed in the connective tissue that existed around the PDLLA (Figure 7(a)). At 2 weeks, the shape of the scaffold had not changed (Figure 8(a)). Many sinusoidal capillaries and connective tissues were observed, and the connective tissue was immature (Figure 8(b)). At 4 weeks, the shape of the scaffold had not changed (Figure 9(a)). More connective tissue was observed in the pores at 4 weeks than at 2 weeks, and the connective tissue had matured (Figure 9(b)). At 12 weeks, the shape of the scaffold had not changed (Figure 10(a)). The amount of connective tissue had decreased, whereas the amount of necrotic tissue had increased; connective tissue without blood vessels had combined 


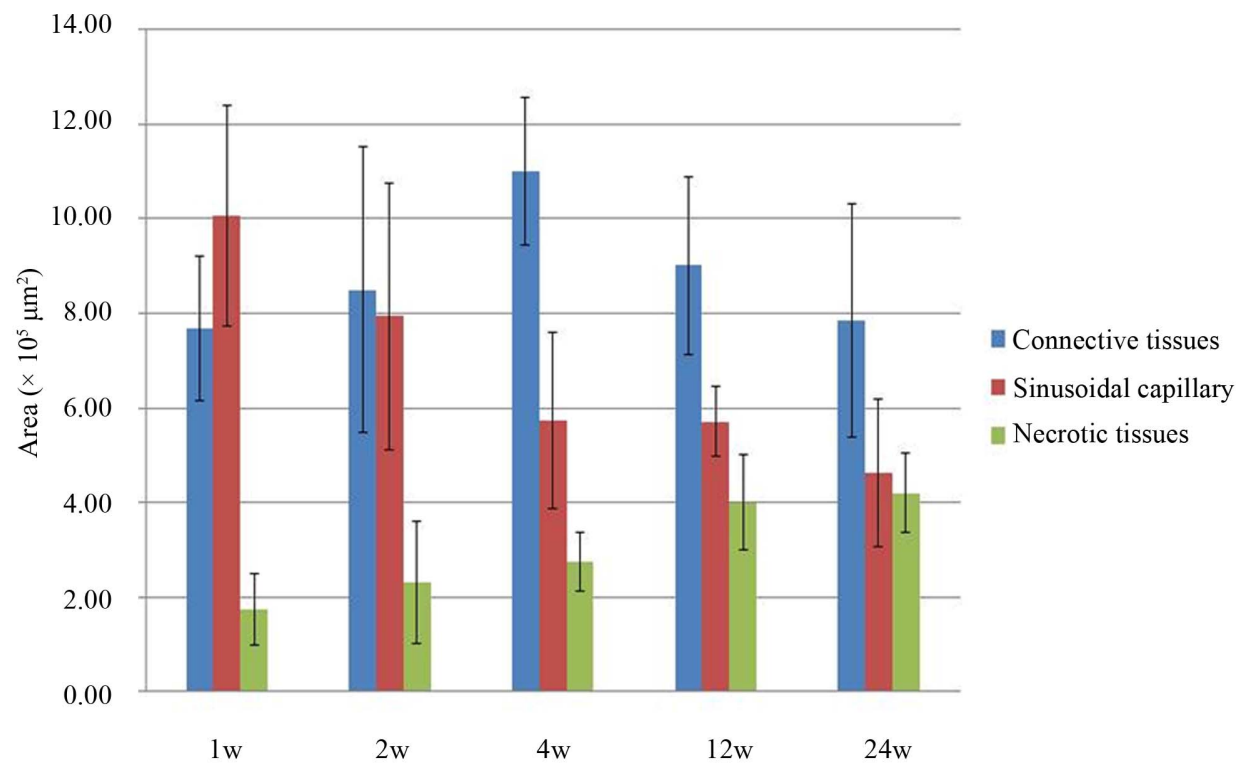

Figure 6. Areas of connective tissue, sinusoidal capillaries, and necrotic tissue measured at different time points.

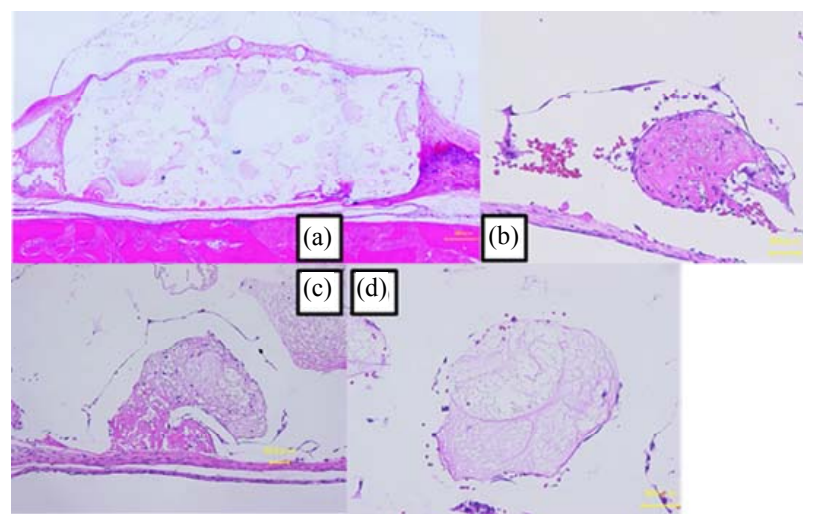

Figure 7. Image of a hematoxylin and eosin-stained paraffinembedded section at 1 week. (a) The shape did not change. The black arrow indicates inflammatory cells (bar, $500 \mu \mathrm{m})$. (b), (c), (d) The connective tissues were immature (bar, $50 \mu \mathrm{m}$ ).

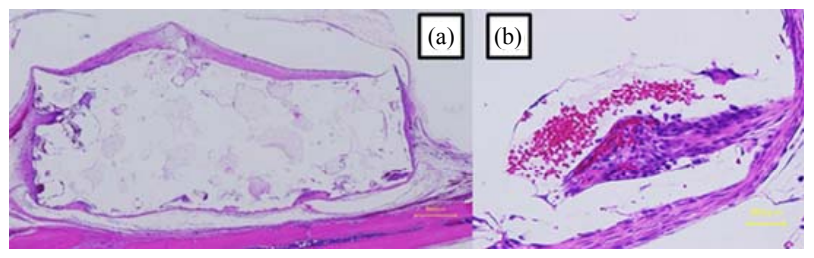

Figure 8. Image of a hematoxylin and eosin-stained paraffinembedded section at 2 weeks. (a) The shape did not change (bar, $500 \mu \mathrm{m}$ ). (b) Connective tissue with sinusoidal capillary (bar, $50 \mu \mathrm{m})$.

with necrotic tissue (Figure 10(b)). At 24 weeks, the corners of the top part of the scaffolds had been resorbed (Figure 11(a)). The connective tissue that survived in the pores contained blood vessels and was more mature (Figure 11(b)).

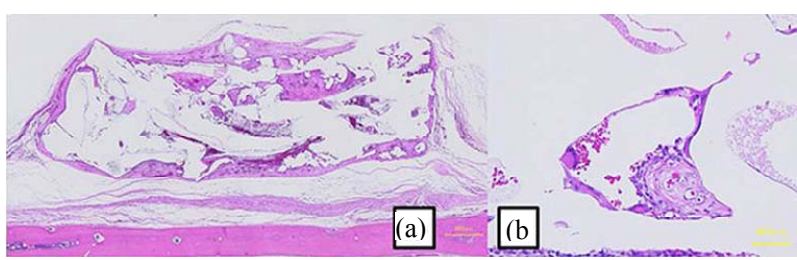

Figure 9. Image of a hematoxylin and eosin-stained paraffinembedded section at 4 weeks. (a) The shape did not change. Connective tissues increased (bar, $500 \mu \mathrm{m}$ ). (b) Connective tissues were mature (bar, $50 \mu \mathrm{m})$.

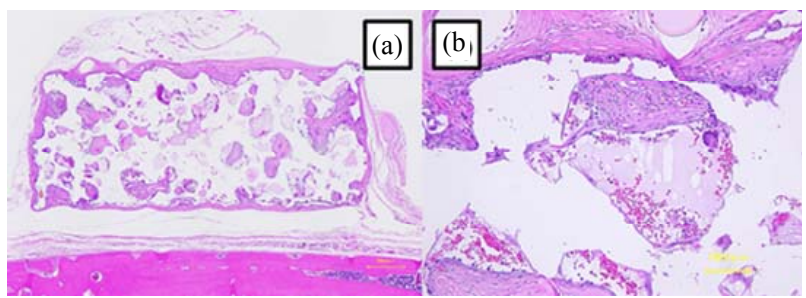

Figure 10. Image of a hematoxylin and eosin-stained paraffinembedded section at 12 weeks. (a) The shape did not change (bar, $500 \mu \mathrm{m}$ ). (b) Connective tissues without blood vessels were observed with necrotic tissues (bar, $30 \mu \mathrm{m}$ ).

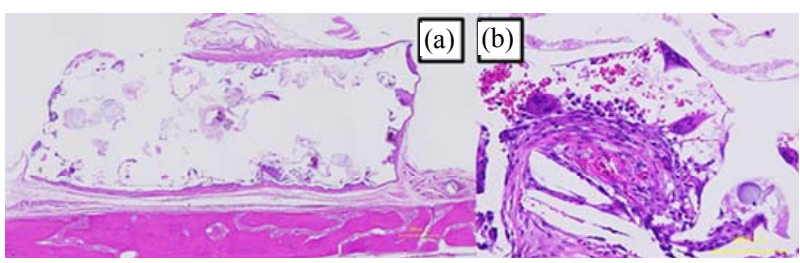

Figure 11. Image of a hematoxylin and eosin-stained paraffinembedded section at 24 weeks. (a) The shape did not change (bar, $500 \mu \mathrm{m}$ ). (b) Connective tissues with blood vessels (bar, $30 \mu \mathrm{m})$ 


\section{DISCUSSION}

Soft tissue augmentation and reconstruction are performed at gingival recession sites. Such operations should be minimally invasive, should not require donor sites, and should be rapid. The materials used in such procedures should be biocompatible, nontoxic, and morphologically stable.

PDLLA has been applied in a variety of medical fields in shapes such as lines, membranes, and screws. Screw shapes have been applied to fix fractured bones [11]. Some in vivo, in vitro, and clinical reports have suggested good biocompatibility and lack of toxicity for PDLLA [12-16]. In this study, inflammatory cells were observed at 1 week as a result of the invasive surgery but were not observed subsequently. Therefore, the results suggest that PDLLA is biocompatible and nontoxic.

It has suggested that eventual resorption of the graft is a drawback of CTG transplantation. Borghetti et al. reported that $76 \%$ of the graft was resorbed [4], which is highly unfavorable for aesthetic improvement. In this study, the scaffolds were measured using a digital caliper. The scaffold height at 24 weeks showed an average decrease of approximately $0.17 \mathrm{~mm}$. In this study, the methods of measured and subject of research were not adaptable with CTG graft transplantation. However, the scaffold materials obviously maintained their morphological features longer than the CTGs described in the literature.

The scaffold materials primarily achieved attachment of cells through exposure to blood and tissue fluid, followed by formation of sinusoidal capillaries. Sinusoidal capillaries have been observed in the liver and bone marrow, which contain various endothelial cells and blood constituents, and are thus important for biocompatibility, nutritional supply, and metabolism. The scaffolds responded to biological encapsulation by connective tissues [17]. Encapsulation caused the materials to be more stable, but it also prevented sinusoidal capillaries from entering and exiting the scaffolds and blocked the nutritional supply and metabolism of engrafted tissue. The encapsulation process thus decreased the amount of immature connective tissue and sinusoidal capillaries, which then changed to necrotic tissue. At 12 weeks, connective tissues with necrotic tissues were observed, which suggests that immature connective tissue developed without blood vessels. At 24 weeks, connective tissues with blood vessels were observed, and these tissues were more mature. Thus, the porous materials generated from PDLLA were initially biocompatible; however, encapsulation subsequently caused a decrease in immature connective tissue in the pores via necrosis. The tissue around the scaffolds was not affected by the necrotic tissue because the encapsulating tissue was robust connective tissue [17], and the tissue around the scaffolds did not show infiltration of inflammatory cells at 12 and 24 weeks.

At 24 weeks, the connective tissue in the pores had decreased but it was mature and stabilized, which suggests that it could survive in the pores indefinitely. The connective tissue clearly contained or was surrounded by blood vessels, and connective tissue without blood vessels was not observed. Blood vessels are critical for cellular nutritional supply and metabolism. Therefore, the penetration of blood vessels is likely necessary to increase and maintain the connective tissue in the pores.

\section{CONCLUSION}

In this study, PDLLA was found to be useful for soft tissue augmentation in the long term. Although the molecular weight of PDLLA decreased with time, the height of the PDLLA scaffolds was preserved. The connective tissue surviving in the pores of the scaffolds at 24 weeks were associated with blood vessels. Further studies are necessary to investigate the optimal scaffold shape and surface characteristics to improve the penetration of blood vessels.

\section{ACKNOWLEDGEMENTS}

This material was supplied by Medical Division, Takiron Co., Ltd, (Japan). I am very grateful to TAKIRON for their valuable cooperation in my experiments.

\section{REFERENCES}

[1] Dahlin, C., Linde, A., Gottlow, J. and Nyman, S. (1988) Healing of bone defects by guided tissue regeneration. Plastic and Reconstructive Surgery, 81, 672-676. http://dx.doi.org/10.1097/00006534-198805000-00004

[2] López-Cerero, L. (2008) Dental implant-related infections. Enfermedades Infecciosas y Microbiología Clínica, 26, 589-592. http://dx.doi.org/10.1157/13128277

[3] Silverstein, L.H., Lefkove, M.D. and Garnick, J.J. (1994) The use of free gingival soft tissue to improve the implant/soft-tissue interface. Journal of Oral Implantology, 20, 36-40.

[4] Borghetti, A., Glise, J.M., Monnet-Corti, V. and Dejou, J. (1999) Comparative clinical study of a bioabsorbable membrane and subepithelial connective tissue graft in the treatment of human gingival recession. Journal of Periodontology, $\quad \mathbf{7 0}, \quad 123-130$. http://dx.doi.org/10.1902/jop.1999.70.2.123

[5] McGuire, M.K. and Nunn, M.E. (2005) Evaluation of the safety and efficacy of periodontal applications of a living tissue-engineered human fibroblast-derived dermal substitute. I. Comparison to the gingival autograft: A randomized controlled pilot study. Journal of Periodontology, 76, 867-880. http://dx.doi.org/10.1902/jop.2005.76.6.867 
[6] Gao, Z.R., Hao, Z.Q., Li, Y., Im, M.J. and Spence, R.J. (1992) Porcine dermal collagen as a wound dressing for skin donor sites and deep partial skin thickness burns. Burns, 18, 492-496.

http://dx.doi.org/10.1016/0305-4179(92)90183-U

[7] Charriere, G., Bejot, M., Schnitzler, L., Ville, G. and Hartmann, D.J. (1989) Reactions to a bovine collagen implant. Clinical and immunologic study in 705 patients. Journal of the American Academy of Dermatology, 21, 1203-1208. http://dx.doi.org/10.1016/S0190-9622(89)70330-3

[8] Rezwan, K., Chen, Q.Z., Blaker, J.J. and Boccaccini, A.R. (2006) Biodegradable and bioactive porous polymer/inorganic composite scaffolds for bone tissue engineering. Biomaterials, 27, 3413-3431. http://dx.doi.org/10.1016/j.biomaterials.2006.01.039

[9] Yang, F., Murugan, R., Ramakrishna, S., Wang, X., Ma, Y.X. and Wang, S. (2004) Fabrication of nano-structured porous PLLA scaffold intended for nerve tissue engineering. Biomaterials, 25, 1891-1900.

http://dx.doi.org/10.1016/j.biomaterials.2003.08.062

[10] Hu, J., Sun, X., Ma, H., Xie, C., Chen, Y.E. and Ma, P.X. (2010) Porous nanofibrous PLLA scaffolds for vascular tissue engineering. Biomaterials, 31, 7971-7977. http://dx.doi.org/10.1016/j.biomaterials.2010.07.028

[11] Leenslag, J.W., Pennings, A.J., Bos, R.R., Rozema, F.R. and Boering, G. (1987) Resorbable materials of poly (L-lactide). VI. Plates and screws for internal fracture fixation. Biomaterials, 8, 70-73. http://dx.doi.org/10.1016/0142-9612(87)90034-2

[12] Hasegawa, S., Neo, M., Tamura, J., Fujibayashi, S., Takemoto, M., Shikinami, Y., Okazaki, K. and Nakamura, T. (2007) In vivo evaluation of a porous hydroxyapa-
tite/poly-DLlactide composite for bone tissue engineering. Journal of Biomedical Materials Research Part A, 81, 930-938. http://dx.doi.org/10.1002/jbm.a.31109

[13] Deplaine, H., Lebourg, M., Ripalda, P., Vidaurre, A., Sanz-Ramos, P., Mora, G., Prósper, F., Ochoa, I., Doblaré, M., Gómez, R.J.L., Izal-Azcárate, I. and Gallego, F.G. (2013) Biomimetic hydroxyapatite coating on pore walls improves osteointegration of poly(L-lactic acid) scaffolds. Journal of Biomedical Materials Research Part B, 101, 173-186. http://dx.doi.org/10.1002/jbm.b.32831

[14] Walsh, W.R., Evans, R.O., Iliopoulos, J., Cornwall, G.B. and Thomas, K.A. (2006) Evaluation of a bioresorbable polylactide sheet for the reduction of pelvic soft tissue attachments in a porcine animal model. Journal of Biomedical Materials Research Part B, 79, 166-175. http://dx.doi.org/10.1002/jbm.b.30527

[15] Shikinami, Y., Okazaki, K., Saito, M., Okuno, M., Hasegawa, S., Tamura, J., Fujibayashi, S. and Nakamura, T. (2006) Bioactive and bioresorbable cellular cubic-composite scaffolds for use in bone reconstruction. Journal of the Royal Society Interface, 3, 805-821. http://dx.doi.org/10.1098/rsif.2006.0144

[16] Simon, Jr., C.G., Eidelman, N., Kennedy, S.B., Sehgal, A., Khatri, C.A. and Washburn, N.R. (2005) Combinatorial screening of cell proliferation on poly(L-lactic acid)/poly (D,L-lactic acid) blends. Biomaterials, 26, 6906-6915. http://dx.doi.org/10.1016/j.biomaterials.2005.04.050

[17] Rozema, F.R., Bos, R.R., Pennings, A.J. and Jansen, H.W. (1990) Poly(L-lactide) implants in repair of defects of the orbital floor: An animal study. Journal of Oral and Maxillofacial Surgery, 48, 1305-1309; Discussion 1310. http://dx.doi.org/10.1016/0278-2391(90)90487-M 